Original Research Paper

\title{
An Empirical Study of Efficiency Evaluation with Dynamic Strategy Trajectory Based on DEA Algorithm and BCG Model: A Case Study of Securities Industry
}

\author{
Cheng-Shian Lin and Chun-Yueh Lin \\ CTBC Business School, Tainan, No.600, Sec. 3, Taijiang Blvd., Annan District, Tainan, Taiwan 709, Taiwan
}

\author{
Article history \\ Received: 25-08-2017 \\ Revised: 25-01-2018 \\ Accepted: 4-04-2018 \\ Corresponding Author: \\ Chun-Yueh Lin \\ CTBC Business School, \\ Tainan, No.600, Sec. 3, \\ Taijiang Blvd., Annan District, \\ Tainan, Taiwan 709 \\ Email: 1jy898@gmail.com
}

\begin{abstract}
The U.S. Subprime Mortgage Crisis in 2008 led many financial institutions, including those in the securities industry, to the verge of bankruptcy. As the securities industry has a pivotal position in financial markets, this study aims to use Data Envelopment Analysis (DEA) to discuss the efficiency of the securities industry after the Financial Tsunami. In addition, this paper integrates the concept of the Boston Consulting Group (BCG) matrix to categorize the efficiency values of the two-stage DEA management strategy and analyze the strategy trajectory. Moreover, to verify whether there is any difference in the efficiency of various stages after the Financial Tsunami, the non-parametric statistical method is used to analyze the single-stage and two-stage efficiency values. Finally, Decision Making Units (DMUs) are clustered according to environmental variables in the literature and significant differences in efficiency are tested in order to understand the impact of environmental variables on the efficiency of the securities industry after the Financial Tsunami. The empirical results can serve as a reference for the securities industry to assess its operational performance and profit performance. In addition, this study provides a tool for securities industry decision-makers to assess business performance after the Financial Tsunami.
\end{abstract}

Keywords: Financial Tsunami, Two-Stage Efficiency, DEA Numerical Method, BCG Matrix

\section{Introduction}

The United States (U.S.) Subprime Mortgage Crisis was one of the causes of the 2008 Global Financial Tsunami and many subprime mortgage-related institutions were on the verge of bankruptcy at that time. Although the U.S. government had taken a variety of measures, including substantial interest rate cuts and a huge capital injection to increase liquidity in the market, the effect was minimal. The subprime mortgage crisis caused a severe global economic recession and by the end of 2008, global industrial production decreased by $20 \%$, global production values hit a new low since World War II and international trade reported negative growth for the first time (WB, 2009). As Taiwan has a trade relationship with the global community, it was unable to avoid this wave of turmoil. Taiwan's exports in 2009 showed a double-digit decline, as shown in Fig. 1. The Taiwan's unemployment rate in
2009 significantly increased by 20 million (DGBAS, 2014). Due to the influence of falling exports, private consumption and investment showed a weak trend. Although Taiwan's government actively stimulated the economy through fiscal spending and monetary policy, it was still unable to effectively lift the overall economy out of decline, as shown in Fig. 2.

The impact of the recession not only hit the U.S. financial system, but also caused considerable panic in the global financial industry, such as the run-on of the British Northern Rock bank, the bankruptcy of Lehman Brothers and the mergers of Bear Stearns and Merrill Lynch by Morgan Stanley and the Bank of America, respectively, with the aid of the U.S. Treasury and the FED (Federal Reserve System). The U.S. Treasury and the FED for the first time bailed out AIG (American International Group). Across the globe, many countries were in financial distress and Taiwan's industries and finance-related industries were seriously affected (Choi, 
2013; Chang and Tu, 2011; Goldsmith-Pinkham and Yorulmazer, 2010; Shin, 2009). Academia has extensively studied the problems generated by the Financial Tsunami, such as the cause and impact of the real estate bubble by the Financial Tsunami (Kang and Liu, 2014; Martin, 2011); the impact of corporate governance on corporate value (Chen, 2014; Erkens et al., 2012); and issues relating to accounting information disclosure and accounting soundness, as well as the impact on companies and investors (Francis et al., 2013).

From the perspective of the financial industry, the bankruptcy of Lehman Brothers triggered panic in the financial industry, as well as many other problems such as run-ons, mergers, credit, loan credit and performance issues (Goedde-Menke et al., 2014; DeYoung and Torna, 2013; Chor and Manova, 2012; Aubuchon and Wheelock, 2010). Some experts have pointed out that performance evaluation is a vital link in financial systems and operations (Chen et al., 2013; Cummins and Weiss, 2013). With global financial liberalization, Taiwan's financial markets have become increasingly important under the trend of globalization. The securities industry is the center of the capital market and it plays an important role in financial markets. After the Financial Tsunami, the differences of the operational size of Taiwan's securities industry increased and the market structure and operational environment of the securities industry have changed considerably. In a highly competitive environment, company strategies should be effectively reviewed and adjusted. Therefore, how to objectively assess the performance of Taiwan's securities industry after the Financial Tsunami is a topic worth exploring.

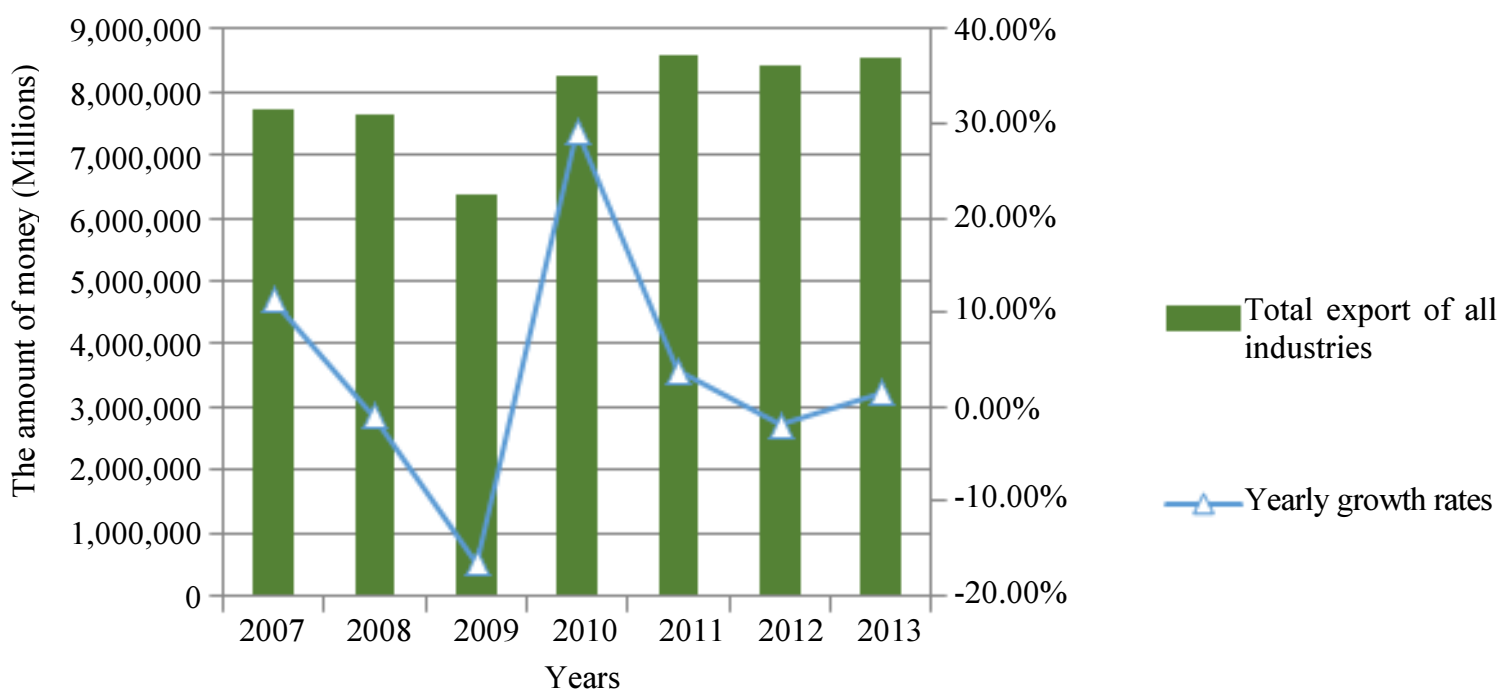

Fig. 1: 2007-2013 Taiwan's total exports and yearly growth rates of all industries

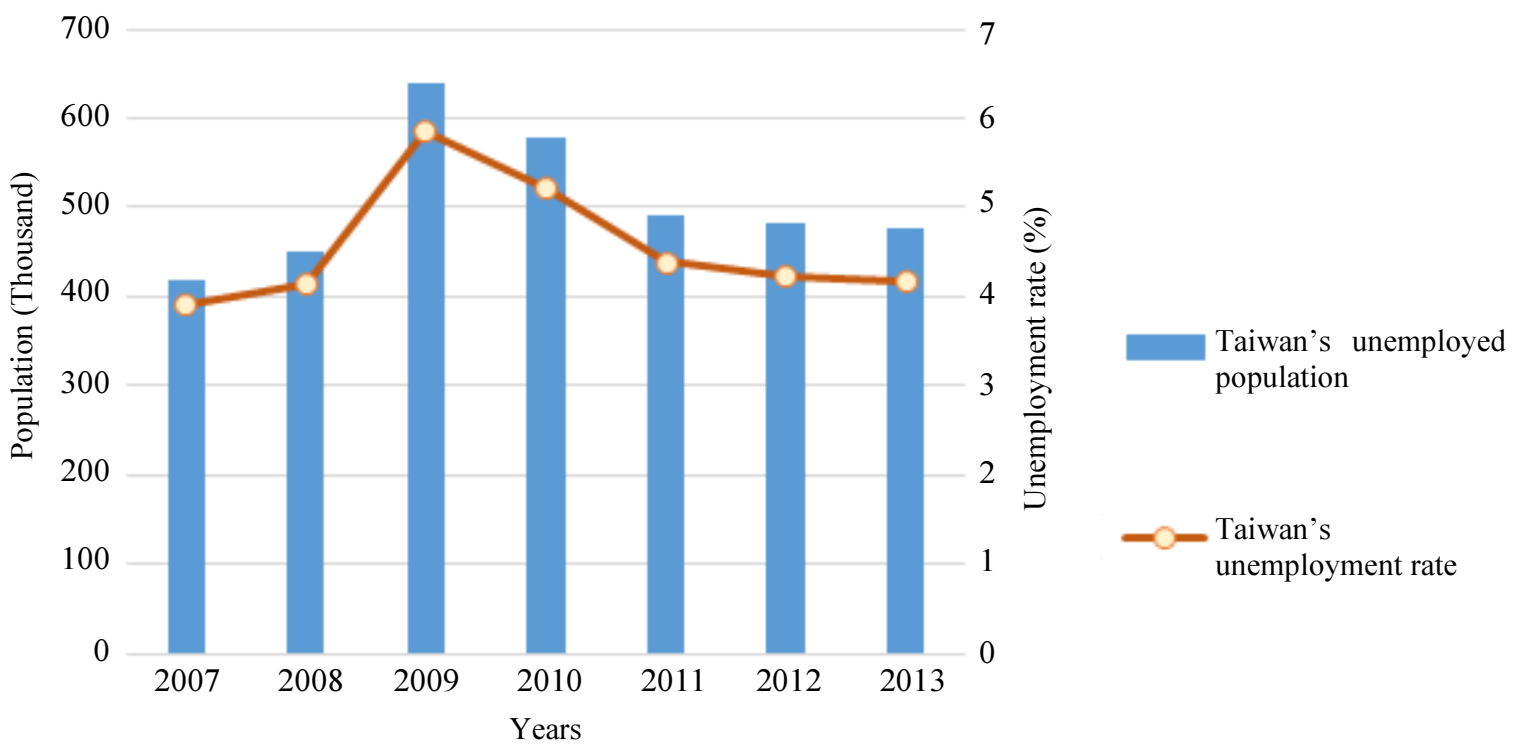

Fig. 2: 2007-2013 Taiwan's unemployed population and unemployment rate 
Business performance can be measured by applying Data Envelopment Analysis (DEA), in the field of finance, DEA is widely applied in performance evaluation (Wang et al., 2014; Barth et al., 2013; Holod and Lewis, 2011). In recent years, DEA has been used extensively in studies on the banking industry, including the evaluation of whether the 45 Greek banks merged or acquired between 2007 and 2011 were able to improve their operational efficiency. Literature has shown that in the year before the financial crisis in Greece, the banks that could be potential targets of merger and acquisitions could not improve their own operational efficiency in a short period of time (Halkos and Tzeremes, 2013). Studies have also used the Bank of Brazil and other samples to conduct efficiency evaluations by comparing banks in Europe with the U.S. and have found that the efficiency of the Bank of Brazil was the lowest (Staub et al., 2010).

The securities industry is the core of the capital market, as it enables the flow of funds in financial markets; hence, it can activate financial markets. In securities markets, the stock market is a leading indicator of economic conditions; thus, the securities industry plays a pivotal role in current financial markets (Liu, 2008). Yeh et al. (2010) evaluated the performance of the securities industry using DEA, the Tobit regression model and corporate governance variables and analyzed and compared 14 financial holding and 12 non-financial holding securities companies' operational efficiency between 2001 and 2007, with capital and labor costs as the input variables and brokerage cost and understanding costs as the output variables. Xiaofang and Kesheng (2009) measured 32 Chinese securities companies, based on DEA and the Malmquist productivity index method and analyzed the technical efficiency of China's securities industry. The results suggested that, while China's securities industry tended to improve in terms of performance, its overall efficiency was relatively low and an increasing number of companies were at the stage of decreasing returns to scale.

For the overall financial industry, empirical evidence regarding the competition and efficiency of the financial service industry is insufficient (Fenn et al., 2008). After the Financial Tsunami, empirical studies on the operational efficiency of the securities industry were few and studies focused on the application of the traditional DEA model. Moreover, the traditional DEA model has obstacles regarding the results of multiple efficiency values (efficiency $=1$ ) and it cannot recognize the overall ranking of efficiency. In addition, past studies did not integrate the BCG model into the DEA results, which could be used to understand the strategy trajectory during the research period. Hence, measurement of the performance of the securities industry by integrating the DEA algorithm (CCR with Super Radial) and the BCG model after the Financial Tsunami urgently requires further study. According to the service value chain, the securities industry can be divided into two stages for the evaluation model. Therefore, two-stage DEA is used to measure the operational performance and profit-making performance of ten securities firms in Taiwan between 2009 and 2013. Moreover, a BCG matrix is used to categorize and analyze management strategies in order to understand the relative efficiency and dynamic track of the securities companies at different stages. Finally, environmental variables are used in difference analysis to understand the impact of environmental variables on the efficiency of the securities industry after the Financial Tsunami. Based on the above, regarding the performance measurement of the financial industry, in most cases, DEA is used to evaluate operational efficiency; however, DEA has the problem of the black box in the evaluation of efficiency, which has not been solved in literature on the basis of the value chain (Ebrahimnejad et al., 2014; Gulati et al., 2017). In efficiency evaluation, DEA generally uses the Charnes, Cooper and Rhodes (CCR) model, which may result in a number of sequences of multiple efficiency values (efficiency $=1$, inefficiency $<1$ ). To address the problem of multiple efficiency values (efficiency $=1$, inefficiency $<1$ ), the Super Radial model is used to separate multiple efficiency samples (efficiency values $=1$ ), in order for the decision-making units (DMUs) without efficiency values to not require analysis. In summary, the Super Radial technique is able to resolve the obstacle of multiple efficiency value results (CCR efficiency $=1$ ) and obtain the actual efficiency value from the CCR results.

The results of DEA can only reveal sample efficiency values and sequences, without providing an understanding of the management strategy or the dynamic strategy trajectory in the years after the Financial Tsunami of the companies. To observe the management strategy and trajectory of the companies, this study integrates the concept of the Boston Consulting Group (BCG) matrix, in which the two-stage DEA efficiency values are categorized by the management strategy and analyzed by the strategy trajectory. Finally, in order to verify whether there are any differences in the performance evaluation model at various stages, this study applies the non-parametric statistical method to analyze single-stage and two-stage efficiency values. Based on studies by Simar and Wilson (2011) and Macpherson et al. (2013), this study clusters the DMUs and tests whether there is any significant difference in efficiency, in order to learn the impact of environmental variables on the securities industry's efficiency after the Financial Tsunami.

To sum up, the research problems of this study include:

- Using two-stage DEA to assess the performance of Taiwan's securities industry

- Using the various efficiency models of DEA in terms of computation efficiency and sequence/ranking 
- Exploring how to integrate DEA's efficiency and the BCG matrix to identify management strategies and strategy trajectories

- Testing the impact of environmental variables on the efficiency of various stages

The purposes of this study are as follows:

- To convert the operational process of the securities industry into two-stage evaluation indicators

- To conduct an efficiency evaluation of the two-stage indicators by the CCR model and apply the Super Radial model in a further analysis of the CCR efficiency values

- To cluster and position the management strategies and trajectories according to the results of the twostage DEA, CCR and Super Radial models

- To analyze the differences of in the impact of environmental variables on the efficiency of the stages by applying the non-parametric statistical method

\section{Research Method}

\section{Pearson Correlational Analysis}

The DEA model has limitations regarding the determination of input and output variables, namely, the selected input and output variables must comply with the principle of isotonicity, which represents that the number of output variables are unable to decrease with the increased output variables. If the results of Pearson Correlational testing between each input and output variable are not significant, it must look for new variables for the Pearson Correlational test model and then, recalculate the significance.

\section{CCR Model}

This study uses DEA as the research method. DEA was first developed by Farrell (1957) according to the concept of Pareto optimality. Farrell first proposed using the production frontier as the basis of efficiency measurement. Under the assumption of the fixed scale of returns of a company, the unit equal production curves are used to illustrate how to use the actual observation points, as well as other equal production curve boundary relationships, to obtain the technical efficiency.

Based on the concept of the production frontier, Charnes et al. (1978) proposed a linear planning performance evaluation method, known as the CCR model, to measure the relative efficiency of the DMUs of multiple inputs and multiple outputs.

If there are $n$ DMUs $(j=1,2, \ldots, n)$, m input variables $(i=1,2, \ldots, m)$ are used to produce output variable $(r=$ $1,2, \ldots, s)$, then, the k-th DMU's efficiency measurement model is:

$$
\operatorname{Max} H_{k}=\frac{\sum_{r=1}^{s} U_{r} Y_{r k}}{\sum_{j=1}^{m} V_{i} X_{i k}}
$$

$$
\begin{aligned}
& \text { s.t. } \quad H_{k}=\frac{\sum_{r=1}^{s} U_{r} Y_{r j}}{\sum_{j=1}^{m} V_{i} X_{i j}} \leq 1, j=1, \ldots, n \\
& U_{r}, V_{i} \geq \varepsilon \geq 0, r=1, \ldots, s, i=1, \ldots, m
\end{aligned}
$$

where, $H_{k}=$ the k-th DMU efficiency value, the r-th output quantity of the $\mathrm{j}$-th DMU, = The I-th input quantity of the j-th DMU, = The r-th output weight, i-th input weight, $\mathrm{n}=$ The DMU quantity, $\mathrm{s}=$ The output quantity, $\mathrm{m}=$ The input quantity and $=$ An infinitely small positive number.

According to Equation (2), the DEA method uses the input item of each DMU output item as the target function and the input items and output items of all DMUs as the limiting conditions. Under the limitation of an efficiency value not greater than 1 , it is possible to obtain the DMU's most favorable input and output item weights, in order for the DMU to have the maximum efficiency value.

\section{Super Radial Model}

As the CCR model computational results may generate a number of efficient DMUs (an efficiency value of 1), it results in a lack of judgment power. For efficient DMUs Andersen and Petersen (1993) further proposed the judgment method, which has no impact on inefficient DMUs. However, the efficiency value of efficient DMUs is re-calculated and the efficiency value is greater than 1. In this way, the efficient DMUs are further sorted (Avkiran, 2011).

If $j$ is the set of all DMUs, then the eliminated $D M U_{k}$ 's efficiency indicator computation method is as follows:

$$
\begin{aligned}
& \operatorname{Min} \theta \\
& \text { s.t. }-\sum_{j \in J-k} \lambda_{j} X_{i j}+\theta X_{i j} \geq 0, i=1, \ldots, m \\
& \sum_{j \in J-k} \lambda_{j} Y_{r j} \geq Y_{r k}, r=1, \ldots, s \\
& \lambda_{j} \geq 0, j \in J-k
\end{aligned}
$$

has no positive or negative limitations.

\section{BCG Matrix}

The BCG matrix (Boston Consulting Group matrix) was proposed by the Boston Consulting Group in 1970 . Its purpose is to facilitate analysis of business and 
product series performance, which helps with the proper distribution of resources; moreover, it is used as an analysis tool for brand establishment and marketing, product management, strategic management and overall business analysis (Haltofová and Štěpánková, 2014).

The BCG matrix is a $2 * 2$ matrix, where the horizontal axis represents the market share, while the vertical axis represents industrial growth and the boundaries of both axes. According to Hedley (1977) and Ioana et al. (2009), the BCG matrix can be divided into four quadrants, with each quadrant representing different types of businesses, as shown in Fig. 3. The four quadrants of the BCG matrix are as follows:

- Cash Cows: Companies in this quadrant typically generate surfeit cash above the amount of cash required to maintain the business. They are regarded as staid and boring in a mature market and all corporations are thrilled to own as many as possible, as they are to be milked continuously with as little investment as possible, since such an investment would be wasted in an industry with low growth (Ioana et al., 2009; Spee and Jarzabkowski, 2009; Hedley, 1977)

- Dogs: Companies in this quadrant are units with low market share in a mature, slow-growing industry, are typically breaking even and generate barely enough cash to maintain the business's market share. As they depress a profitable company's return on assets ratio, many investors use them to judge how well a company is being managed (Ioana et al., 2009; Spee and Jarzabkowski, 2009; Hedley, 1977)

- Question Marks: Companies in this quadrant are growing rapidly and thus consume large amounts of cash; however, they have low market shares and low cash. The result is large net cash consumption. A question mark has the potential to gain market share and become a star and eventually a cash cow when market growth slows down. If a question mark does not succeed in becoming a market leader, perhaps after years of cash consumption, it will degenerate into a dog when market growth declines. Question Marks must be carefully analyzed in order to determine whether they are worth the investment required to grow market shares (Ioana et al., 2009; Spee and Jarzabkowski, 2009; Hedley, 1977)

- Stars: Companies in this quadrant have high market share in a fast-growing industry and the hope is that Stars become the next Cash Cows. While sustaining the business unit's market leadership may require extra cash, this is worthwhile if it allows the unit to remain a leader. When growth slows down, Stars become Cash Cows if they have been able to maintain their category leadership, or the move from brief stardom to dogdom (Ioana et al., 2009; Spee and Jarzabkowski, 2009; Hedley, 1977).

As an industry and the market gradually become mature, all companies in the industry will become businesses in the area of Cash Cows or Dogs. The life cycle of most businesses starts in the area of Question Marks and shift to the area of Stars. When market growth slows down, it will shift to the area of Cash Cows and ultimately shift to the area of Dogs to complete a life cycle.

Through the concept of the BCG matrix and implementation of the two-stages of DEA (operational efficiency and profit-making efficiency), the BCG matrix includes a $2 * 2$ matrix, where the horizontal axis indicates operating efficiency, while the vertical axis represents profit efficiency and the boundaries of both axes. The performance and dynamic management strategies of the securities industry after the Financial Tsunami are analyzed. First, the DEA analysis results of the operational efficiency and profit-making efficiency of the securities firms are input into the BCG matrix before introducing the operational efficiency and profitmaking efficiency of the recent five years into the BCG matrix, in this way, it is possible to obtain the trends of dynamic management strategies.

\section{Non-Parametric Statistics}

As single-stage and two-stage samples are mutually dependent, this study uses the Wilcoxon signed rank test method of mutually dependent non-parametric statistics in order to conduct difference analysis of the two-stage and single-stage samples. As the sample environmental variable consists of two independent samples, this study uses the Mann-Whitney $U$ test method for the two independent samples $\eta_{1}$ and $\eta_{2}$ of non-parametric statistics to conduct difference testing of the environmental variables.

\section{Mann-Whitney U Test Method}

The Mann-Whitney U test method, as proposed by Mann and Whitney (1947), assumes that two samples come from two identical matrices, with the exception of the two overall mean values. Its purpose is to test whether the mean values of the two parameters have a significant difference.

This test method can be applied in testing regardless of whether the two parametric means of $\eta_{1}$ and $\eta_{2}$ are the same, or whether the variances of the two matrices are the same; however, the two tests cannot be conducted simultaneously. 


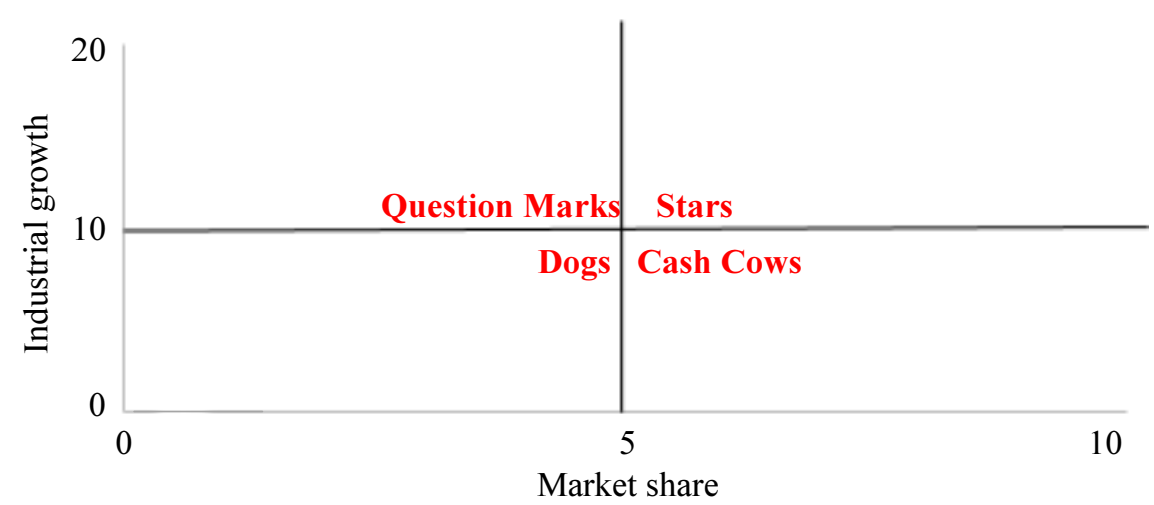

Fig. 3: Original BCG matrix diagram

The theoretic basis of the Mann-Whitney $U$ test method is that the observation values of two groups of samples and, will be very close in a twined arrangement if the two independent samples come from the same two parameters of equal mean values. Otherwise, the test statistics of $U$ must be small and should be rejected, suggesting that the parameters may not be consistent or the mean values are different.

\section{Wilcoxon Signed Rank Test Method}

The Wilcoxon signed rank test method is used to test whether the mean values of the parameters of the two related samples have significant differences. If only the negative and positive symbol of each pair's observation value difference $D$ is considered and without considering the size of the difference, the information of the samples cannot be fully used. As the testing results are not desirable, Wilcoxon provides a symbol grade testing method of practical value (Wilcoxon, 1970).

The Wilcoxon signed rank test method tests whether the two parameters have the same mean values, or the two samples come from the same parameter. Those with observation value difference $D$ at 0 should be eliminated before ranking by the absolute values of the differences. If there are two or more absolute values, the ranking of each is given before obtaining the mean value of the grades and the mean grade is used as the grade of the same differences.

The theoretical basis of the Wilcoxon signed rank test method is that if the mean values of the two related samples have no significant difference, namely $\eta_{D}$ is 0 , then the positive sign grade $\mathrm{W}(+)$ sum and negative sign grade W (-) sum are extremely close; therefore, if the grade sum is too great or too small, namely, $\mathrm{W}$ is small, the mean values of the two parameters are not likely to be equal and $\eta_{D}$ is unlikely to be 0 ; therefore, $\mathrm{H}_{0}$ should be rejected.

\section{Empirical Results and Analysis}

\section{DMU Selection}

The research samples are measured by annual data and the research subjects are non-financial holding securities dealers in Taiwan. The ten samples of this study are as follows: President Securities (PSC), MasterLink Securities (ML), Concord International Securities (CIS), KGI Securities (KGI), Horizon Securities (HRS), Concord Securities (CCS), Tachan Securities (TCS), Ta Ching Securities (TCHS), Ta Chong Securities (TCSC) and CAPITAL Securities (CAPITAL).

\section{Data Sources}

In this study, securities dealers are analyzed in the period after the Financial Tsunami and the research period is from December $31^{\text {st }}, 2009$ to December $31^{\text {st }}, 2013$.

The major data sources include:

- Taiwan Economic Journal (TEJ)

- Taiwan Stock Exchange Market Observation Post System

- Creates Morn Money Investment Decision Support System

- Taiwan Securities Association

Through relevant literature and the industrial characteristics of the securities industry, this study determines the input and output variables and categorizes them into two stages for analysis (Fang and $\mathrm{Hu}, 2012$; Xiaofang and Kesheng, 2009). Stage I is the operational stage and Stage II is the profit-making stage. The operational stage input variables include operational expenses and total assets, while the output variables include the number of employees and equipment. The profit-making stage input variables are the operational stage output variables; therefore, the profit-making stage input variables include the number of employees and equipment, while the output variables include brokerage revenues, underwriting revenues, self-operating business revenues and interest revenues. The input and output variables of the operational stage and profit-making stage are shown in Fig. 4. The mean value of the operational expenses of the ten securities firms is NTD $2,458,752,000$ and the mean value of the total assets is NTD 42,391,909,000. The basic statistics of the variables are shown in Table 1. 


\begin{tabular}{lcc}
\hline Stage & \multicolumn{1}{c}{ Input variables and output variables } \\
\hline Stage I & Input & Output \\
\hline $\begin{array}{l}\text { Operatio } \\
\text { nal stage }\end{array}$ & $\begin{array}{c}\text { Operational } \\
\text { expenses } \\
\text { Total assets }\end{array}$ \\
\hline Stage II & $\begin{array}{c}\text { The number of } \\
\text { employees } \\
\text { Equipment } \\
\begin{array}{l}\text { Profit-m } \\
\text { aking } \\
\text { stage }\end{array}\end{array}$ & $\begin{array}{c}\text { Input } \\
\text { Equipment }\end{array}$ \\
\hline
\end{tabular}

Fig. 4: Flowchart of two-stage input/output variables

Table 1: Basic statistics of the variables of the ten securities firms Unit: Thousand (NTD)

\begin{tabular}{llllll}
\hline Variables & Average & Maximum & Minimum & Standard deviation & Variance \\
\hline Operational expenses & $2,458,752$ & $2,710,391$ & $2,225,775$ & $207,131.15$ & 34322651131 \\
Total assets & $42,391,909$ & $53,392,578$ & $37,027,305$ & $7,325,456.73$ & $4.29299 \mathrm{E}+13$ \\
The number of employees & 1,332 & 1,471 & 1,130 & 126.00 & 12701.59 \\
Equipment & 610,071 & 686,676 & 544,990 & $55,610.50$ & 2474022327 \\
Brokerage revenues & $1,894,391$ & $2,320,388$ & $1,522,745$ & $336,458.53$ & 90563478628 \\
Underwriting revenues & 97,951 & 130,323 & 49,777 & $324,38.85$ & 841823526.4 \\
Self-operating business revenues & $9,599,456$ & $13,013,651$ & $8,092,428$ & $2,016,531.53$ & $3.25312 \mathrm{E}+12$ \\
Interest revenues & 696,025 & 831,840 & 555,394 & $121,819.71$ & 11872034248 \\
\hline
\end{tabular}

\section{Correlation Analysis of the Input and Output Variables}

As the input and output variable data of the DEA method should comply with the relationship of isotonicity, if the variables are negatively correlated, they must be eliminated. This study conducts Pearson correlation testing of the input and output items in order to confirm that the variable data are in line with the theoretical requirements of isotonicity and finds that the eight variables are positively correlated from 2009 to 2013.

\section{Comparison of Efficiency Values of the CCR and Super Radial (SR) Models}

According to the original data of TEJ from 2009 to 2013, through the Pearson correlation results, it can be concluded that the two-stage input and output variables are positively correlated. CCR is used to assess the operational efficiency and profit-making efficiency of securities firms. If the efficiency value is 1 , it means the sample has relative efficiency; on the contrary, if the efficiency value is smaller than 1 , it is inefficient. Moreover, a smaller efficiency value means the sample's efficiency is poorer. However, as CCR results will have more efficiency values (efficiency $=1$, inefficiency $<1$ ), a complete ranking cannot be conducted. Therefore, to solve the problem of CCR having an efficiency value (efficiency $=1$, inefficiency $<1$ ), this study uses the Super Radial method (SR) to separate and sort some efficient samples (efficiency values $=1$, inefficiency $<1$ ). It is not necessary to analyze securities firms without efficiency values. The results suggest that, at the operational stage in 2009, CIS and TCS were efficient, while the remaining eight securities firms were inefficient. At the profit-making stage, HRS, TCS and CAPITAL were efficient, while the remaining seven securities firms were not efficient. At the 2010 operational stage, only TCS was efficient, while the remaining nine securities firms were inefficient. At the profit-making stage, KGI, HRS, CCS, TCS, TCSC and CAPITAL were efficient, while the remaining four securities firms were inefficient. At the 2011 operational stage, CIS, TCS and TCHS were efficient, while the remaining seven securities firms were inefficient. At the profit-making stage, PSC, ML, KGI, HRS, TCS and CAPITAL were efficient, while the remaining four securities firms were inefficient. At the 2012 operational stage, CIS and TCS were efficient, while the remaining eight securities firms were inefficient. At the profit-making stage, PSC, ML, KGI, CCS and CAPITAL were efficient, while the remaining five securities firms were inefficient. At the 2013 operational stage, CIS and TCS were efficient, while the remaining eight securities firms were inefficient. At the profit-making stage, PSC, KGI, CCS and CAPITAL were efficient, while the remaining six securities firms were inefficient. It can be concluded that the remaining six securities firms were inefficient. It can be learned from the above that TCS was efficient at the operational stage from 2009 to 2013, while CAPITAL was efficient at the profitmaking stage from 2009 to 2013.

The CCR results have more efficiency values (efficiency values $=1$ ); therefore, this study uses SR in analysis and further determines the sequence. At the operational stage in 2009, TCS and CIS were efficient. After the ranking of SR, the results suggest TCS (2.005) was greater than CIS (1.965). At the profit-making stage in 
2009, CAPITAL, HRS and TCS were efficient. After the ranking of SR, the results suggest that CAPITAL (2.001) was greater than HRS (1.973) and TCS (1.326). The analysis results from 2009 to 2013 are shown in Tables 2-4.

\section{BCG Dynamic Strategy Analysis}

The DEA results can be used to understand the samples' efficiency values and sequence, but they cannot provide an understanding of the management and dynamic management strategies in the years after the
Financial Tsunami. Thus, this study integrates the concept of the BCG matrix to categorize and analyze the management strategies of the two-stage DEA efficiency values. According to Spee and Jarzabkowski (2009), the BCG matrix can be divided into four quadrants: Stars, Question Marks, Dogs and Cash Cows. In this paper, the $\mathrm{X}$-axis is defined as operational performance; while the Y-axis is defined as profit performance. As shown in Fig. 5, CCR and SR are used to observe the management strategies and trajectory of the BCG companies.

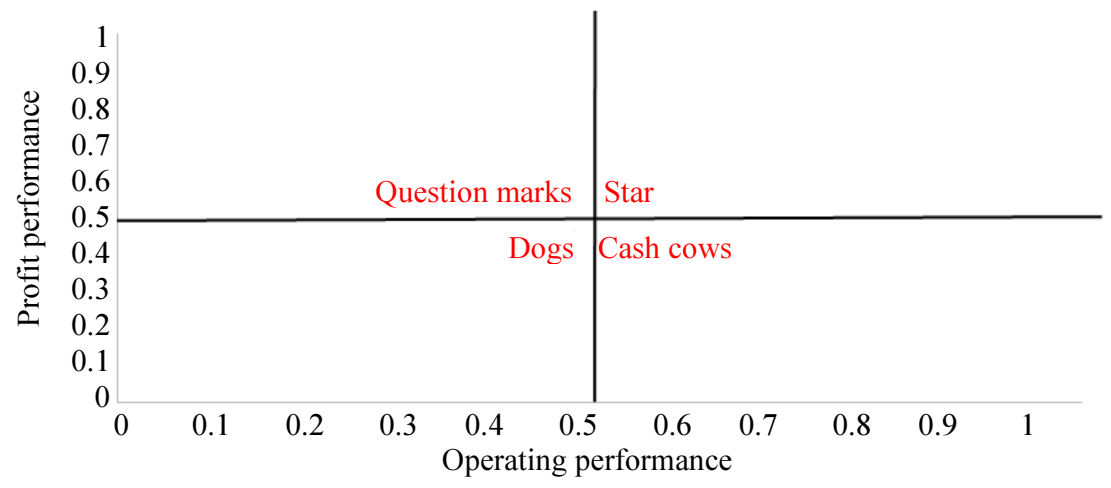

Fig. 5: BCG efficiency matrix

Table 2: Comparison of the CCR and Super Radial (SR) models' efficiency values

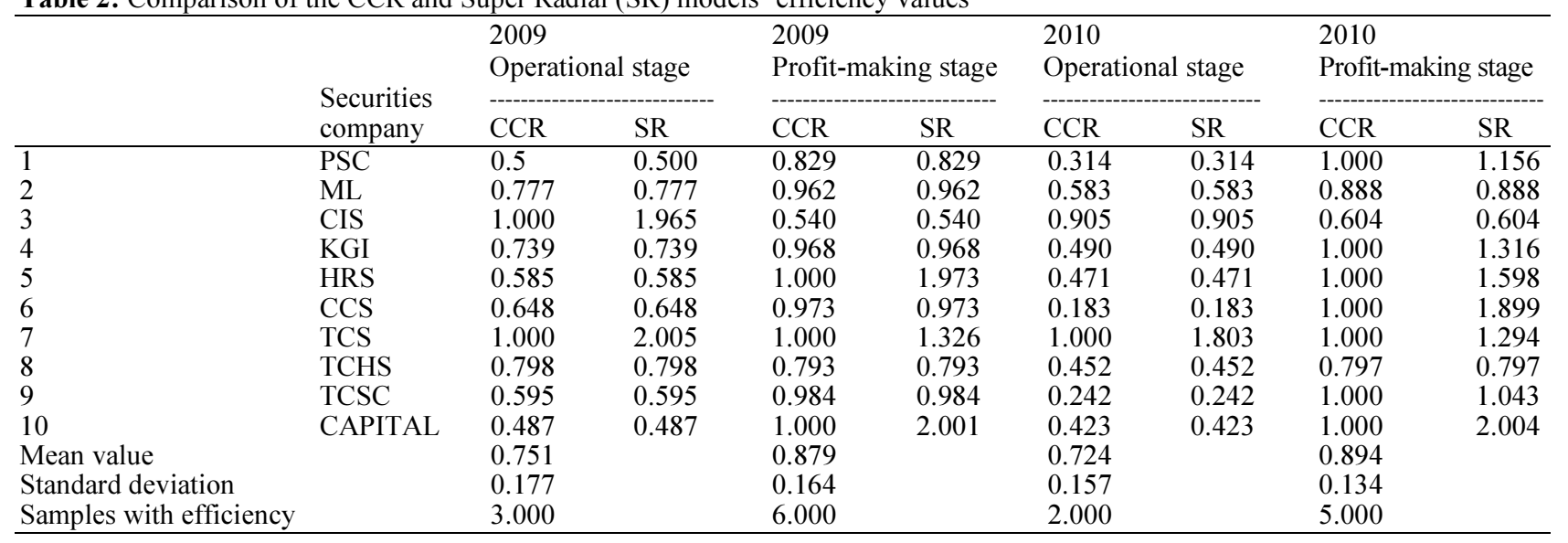

Table 3: Comparison of the CCR and Super Radial (SR) models' efficiency values (continued)

\begin{tabular}{|c|c|c|c|c|c|c|c|c|c|}
\hline & \multirow{2}{*}{$\begin{array}{l}\text { Securities } \\
\text { Company }\end{array}$} & \multicolumn{2}{|c|}{$\begin{array}{l}2009 \\
\text { Operational stage }\end{array}$} & \multicolumn{2}{|c|}{$\begin{array}{l}2011 \\
\text { Profit-making stage }\end{array}$} & \multicolumn{2}{|c|}{$\begin{array}{l}2012 \\
\text { Operational stage }\end{array}$} & \multicolumn{2}{|c|}{$\begin{array}{l}2012 \\
\text { Profit-making stage }\end{array}$} \\
\hline & & CCR & SR & CCR & SR & CCR & SR & CCR & SR \\
\hline 1 & PSC & 0.519 & 0.519 & 1.000 & 1.514 & 0.595 & 0.595 & 1.000 & 1.257 \\
\hline 2 & ML & 0.751 & 0.751 & 1.000 & 1.008 & 0.722 & 0.722 & 1.000 & 1.764 \\
\hline 3 & CIS & 1.000 & 1.723 & 0.548 & 0.548 & 1.000 & 1.412 & 0.589 & 0.589 \\
\hline 4 & KGI & 0.600 & 0.600 & 1.000 & 1.274 & 0.625 & 0.625 & 1.000 & 1.196 \\
\hline 5 & HRS & 0.684 & 0.684 & 1.000 & 1.134 & 0.635 & 0.635 & 0.868 & 0.868 \\
\hline 6 & $\mathrm{CCS}$ & 0.666 & 0.666 & 0.834 & 0.834 & 0.647 & 0.647 & 1.000 & 1.130 \\
\hline 7 & TCS & 1.000 & 2.507 & 1.000 & 1.245 & 1.000 & 2.432 & 0.928 & 0.928 \\
\hline 8 & TCHS & 1.000 & 1.086 & 0.643 & 0.643 & 0.827 & 0.827 & 0.749 & 0.749 \\
\hline 9 & TCSC & 0.733 & 0.733 & 0.767 & 0.767 & 0.658 & 0.658 & 0.808 & 0.808 \\
\hline 10 & CAPITAL & 0.554 & 0.554 & 1.000 & 1.655 & 0.531 & 0.531 & 1.000 & 1.505 \\
\hline \multicolumn{3}{|c|}{ Mean value } & 0.751 & & 0.879 & & 0.724 & & 0.894 \\
\hline \multicolumn{3}{|c|}{ Standard deviation } & 0.177 & & 0.164 & & 0.157 & & 0.134 \\
\hline \multicolumn{3}{|c|}{ Samples with efficiency } & 3.000 & & 6.000 & & 2.000 & & 5.000 \\
\hline
\end{tabular}


Table 4: Comparison of the CCR and Super Radial (SR) models' efficiency values (continued)

\begin{tabular}{|c|c|c|c|c|c|}
\hline & \multirow[b]{2}{*}{ Securities company } & \multicolumn{2}{|c|}{2013 Operational stage 2013} & \multicolumn{2}{|c|}{ Profit-making stage } \\
\hline & & CCR & SR & CCR & SR \\
\hline 1 & PSC & 0.422 & 0.422 & 1 & 1.07 \\
\hline 2 & ML & 0.654 & 0.654 & 0.811 & 0.811 \\
\hline 3 & CIS & 1 & 1.663 & 0.397 & 0.397 \\
\hline 4 & KGI & 0.395 & 0.395 & 1 & 1.697 \\
\hline 5 & HRS & 0.667 & 0.667 & 0.801 & 0.801 \\
\hline 6 & $\mathrm{CCS}$ & 0.398 & 0.398 & 1 & 1.419 \\
\hline 7 & TCS & 1 & 2.296 & 0.913 & 0.913 \\
\hline 8 & TCHS & 0.75 & 0.75 & 0.591 & 0.591 \\
\hline 9 & TCSC & 0.563 & 0.563 & 0.57 & 0.57 \\
\hline 10 & CAPITAL & 0.456 & 0.456 & 1 & 1.138 \\
\hline Mean value & 0.63 & & 0.808 & & \\
\hline Standard deviation & 0.218 & & 0.207 & & \\
\hline Samples with efficiency & 2 & & 4 & & \\
\hline
\end{tabular}

Regarding the ML sample in CCR, this paper uses the CCR and SR results for dynamic analysis. From 2009 to 2013, the dynamic management strategies were all in the quadrant of Stars, suggesting that ML had better performance in terms of operational and profitmaking efficiency during the five years and that in particular, the profit-making efficiency of 2012 was the best. According to the financial statements, in 2011 and 2012, the self-operating business revenues (including bonds and new financial products) were significantly greater than the 2012 self-operating business revenues by nearly $100 \%$, which could be the optimal reason for the profit-making efficiency of 2012. Regarding PSC's management strategies, the dynamic analysis of CCR and SR results suggests that PSC's dynamic management strategies were in the quadrant of Stars in 2009. In 2010, it set up joint mutual funds in mainland China and purchased U.S. currency market funds. As a result, the operational costs increased, while operational efficiency decreased; therefore, the 2010 dynamic track was in the quadrant of Question Marks. In 2011, new shares were issued by converting earnings. The capitalization was used to enrich the operating capital and resulted in increased operational and profit-making efficiency; hence, PSC was in the quadrant of Stars in 2011. In 2012, without specific major influential measures, it remained in the quadrant of Stars. Finally, it planned to invest in setting up new offspring companies, resulting in increased operational costs. As a result, in 2013, it was in the quadrant of Question Marks. The analysis of the results of the remaining companies is shown in Fig. 6.

\section{Test of Environment Variables}

The business process of the securities industry is converted into the two-stage evaluation process. To analyze the differences between the single-stage and two-stage performance evaluation models, this study uses the non-parametric statistical method for the difference analysis of single-stage and two-stage efficiency values. As the samples of this research are
10 DMUs, the data category is a small sample size; therefore, the characteristics of non-parametric statistics are appropriate for verifying small samples (Gibbons, 1993). Accordingly, this study utilizes nonparametric statistics to examine the significant variances of the environmental variables and the original data are shown in Table 5. The results suggest that the single-stage and two-stage efficiency values have significant differences. The analysis results are shown in Table 6 . The results indicate that the traditional single-stage DEA model is different from the two-stage model and the two-stage model is more meaningful. In addition, the literature suggests that company size (large and small), establishment time (new and old) and service size (large and small) are important for performance measurement and are defined as environmental variables (Simar and Wilson, 2011; Macpherson et al., 2013). The classification of all efficiency values based on environmental variables are shown in Table 7 and 9. Based on the environmental variables, this study conducts a difference analysis in order to understand the impact of the environmental variables after the Financial Tsunami on the efficiency of the securities industry. The results suggest that, at the operational stage and the profit-making stage, company size (large and small), establishment time (new and old) and service size (large and small) are not significant, suggesting that the operational and profit-making efficiency of the securities industry after the Financial Tsunami are not affected by size (large and small), establishment time (new and old), or service size (large and small). The analysis results are shown in Table 10, which indicates that, in 2008, the factors of organization size, whether a new or old company and the scope of the enterprise are not influenced by operational efficiency or profit-making after the financial crisis. It might be that the performance of the securities industry in Taiwan depends on the global economy, prosperity and the business cycle. 
Table 5: Five-year average efficiency values at the single-stage and two-stage

\begin{tabular}{|c|c|c|c|c|c|}
\hline & & \multicolumn{2}{|l|}{ CCR } & \multicolumn{2}{|l|}{ SR } \\
\hline & & Single-stage & Two-stage & Single-stage & Two-stage \\
\hline 1 & PSC & 0.955 & 0.718 & 0.973 & 0.818 \\
\hline 2 & ML & 1.000 & 0.815 & 1.317 & 0.892 \\
\hline 3 & CIS & 1.000 & 0.758 & 1.308 & 1.035 \\
\hline 4 & KGI & 0.965 & 0.782 & 0.991 & 0.930 \\
\hline 5 & HRS & 0.990 & 0.771 & 1.539 & 0.942 \\
\hline 6 & $\mathrm{CCS}$ & 1.000 & 0.735 & 1.098 & 0.880 \\
\hline 7 & TCS & 0.975 & 0.984 & 1.293 & 1.675 \\
\hline 8 & TCHS & 1.000 & 0.740 & 1.153 & 0.749 \\
\hline 9 & TCSC & 0.859 & 0.692 & 0.859 & 0.696 \\
\hline 10 & CAPITAL & 1.000 & 0.745 & 1.371 & 1.076 \\
\hline
\end{tabular}

Table 6: Statistical results of the single-stage and two-stage

\begin{tabular}{|c|c|c|c|c|}
\hline & \multicolumn{2}{|l|}{ CCR } & \multicolumn{2}{|l|}{ SR } \\
\hline & Single-stage & Two-stage & Single-stage & Two-stage \\
\hline Z-TEST & -2.803 & & -2.090 & \\
\hline Asymptotic significance (two-tailed) & $0.005 * *$ & & $0.037 *$ & \\
\hline
\end{tabular}

$* *$ When significance level is 0.01 (two-tailed), they are significantly correlated

*When significance level is 0.05 (two-tailed), they are significantly correlated

Table 7: Environmental variables-company size Unit: Thousand

\begin{tabular}{|c|c|c|c|c|}
\hline \multirow[b]{2}{*}{ Securities company } & \multicolumn{4}{|l|}{ SR } \\
\hline & Operational stage & Profit-making stage & The value of total assets & Classification \\
\hline PSC & 0.420 & 1.123 & $50,719,318$ & Large \\
\hline ML & 0.671 & 0.921 & $68,751,432$ & \\
\hline CAPITAL & 0.454 & 1.578 & $69,824,891$ & \\
\hline KGI & 0.514 & 1.148 & $169,072,843$ & \\
\hline CIS & 1.361 & 0.472 & $3,472,174$ & \\
\hline TCS & 1.963 & 0.956 & $4,659,995$ & Small \\
\hline TCHS & 0.733 & 0.605 & $8,394,711$ & \\
\hline HRS & 0.549 & 1.190 & $10,777,612$ & \\
\hline TCSC & 0.499 & 0.765 & $12,722,702$ & \\
\hline CCS & 0.464 & 1.123 & $25,523,415$ & \\
\hline Mean value & & & $42,391,909$ & \\
\hline
\end{tabular}

Note: if the value of total assets is greater than the mean value, it is a large company; otherwise, it is a small company

Table 8: Environmental variables-establishment time Unit: Year

\begin{tabular}{|c|c|c|c|c|}
\hline \multirow[b]{2}{*}{ Securities company } & \multicolumn{4}{|l|}{ SR } \\
\hline & Operational stage & Profit-making stage & The establishment time & Classification \\
\hline $\mathrm{ML}$ & 0.698 & 1.087 & 1989 & New \\
\hline CIS & 1.534 & 0.536 & 1989 & \\
\hline TCSC & 0.558 & 0.834 & 1989 & \\
\hline $\mathrm{CCS}$ & 0.509 & 1.251 & 1990 & \\
\hline HRS & 0.608 & 1.554 & 1961 & Old \\
\hline CPAITAL & 0.491 & 1.661 & 1977 & \\
\hline PSC & 0.470 & 1.165 & 1988 & \\
\hline KGI & 0.570 & 1.290 & 1988 & \\
\hline TCS & 2.209 & 1.141 & 1988 & \\
\hline TCHS & 0.783 & 0.715 & 1988 & \\
\hline
\end{tabular}


Cheng-Shian Lin and Chun-Yueh Lin / Journal of Social Sciences 2018, Volume 14: 91.106 DOI: $10.3844 /$ jssp.2018.91.106

Table 9: Environmental variables- service size Unit: Number of branches

\begin{tabular}{|c|c|c|c|c|}
\hline \multirow[b]{2}{*}{ Securities company } & \multicolumn{4}{|l|}{ SR } \\
\hline & Operational stage & Profit-making stage & The number of branches & Classification \\
\hline KGI & 0.570 & 1.414 & 84 & Large \\
\hline CPAITAL & 0.491 & 1.661 & 62 & \\
\hline ML & 0.698 & 1.247 & 49 & \\
\hline PSC & 0.470 & 1.384 & 37 & \\
\hline $\mathrm{CCS}$ & 0.509 & 1.330 & 22 & \\
\hline TCSC & 0.558 & 0.961 & 16 & \\
\hline TCHS & 0.783 & 0.772 & 14 & Small \\
\hline HRS & 0.608 & 1.554 & 11 & \\
\hline CIS & 1.534 & 0.558 & 10 & \\
\hline TCS & 2.209 & 1.141 & 2 & \\
\hline Mean value & & & 43 & \\
\hline
\end{tabular}

Note: if the number of branches is greater than the mean value, it is a large size; otherwise, it is a small size

Table 10: Statistical results of environmental variables

\begin{tabular}{lllllll}
\hline & Company size & Company size & Establishment time & Establishment time & Service size & Service size \\
& Operational stage & Profit-making stage & Operational stage & Profit-making stage & Operational stage & Profit-making stage \\
\hline Mann-Whitney $U$ & 5 & 4 & 11 & 5 & 8 & 4 \\
Wilcoxon $W$ & 15 & 25 & 32 & 15 & 14 & 32 \\
$Z$-TEST & -1.492 & -1.706 & -0.213 & -1.492 & -0.57 & -1.481 \\
P-value & 0.171 & 0.114 & 0.914 & 0.171 & 0.569 & 0.138 \\
\hline
\end{tabular}

**Represents $1 \%$ significance level (two-tailed)

\section{PSC CCR Efficiency value}

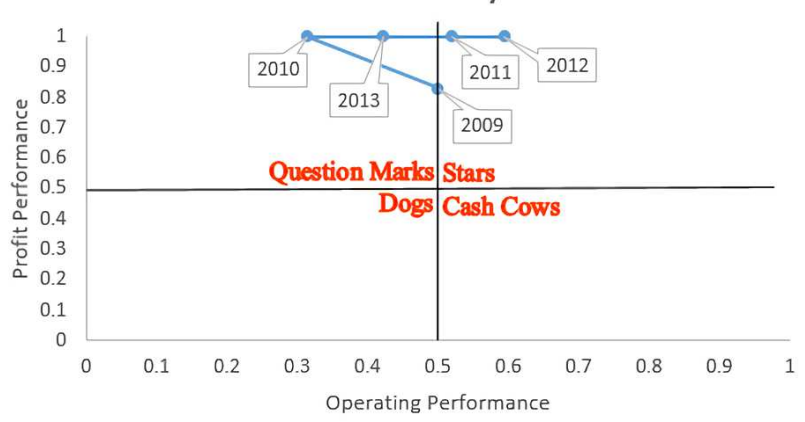

ML CCR Efficiency value

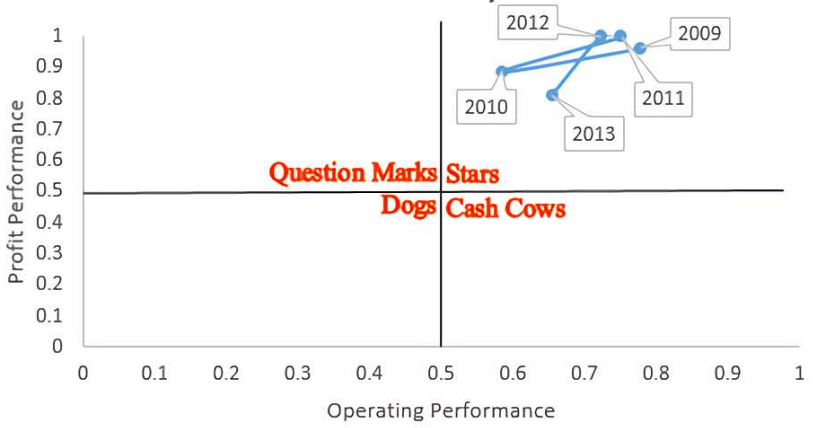

PSC SR Efficiency value

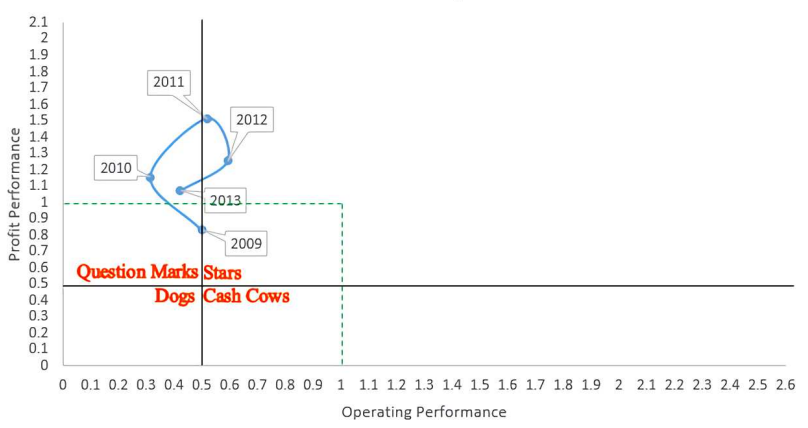

ML SR Efficiency value

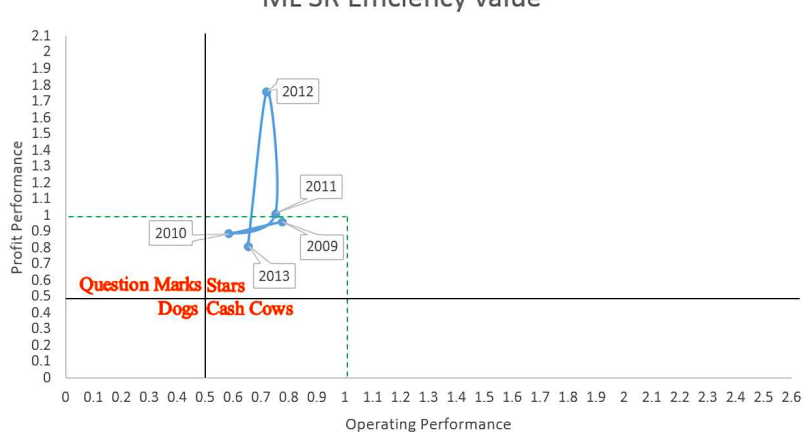




\section{CIS CCR Efficiency value}

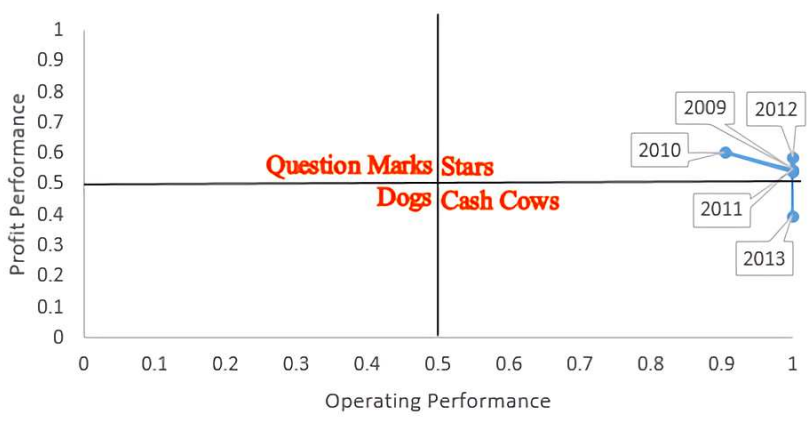

CIS SR Efficiency value

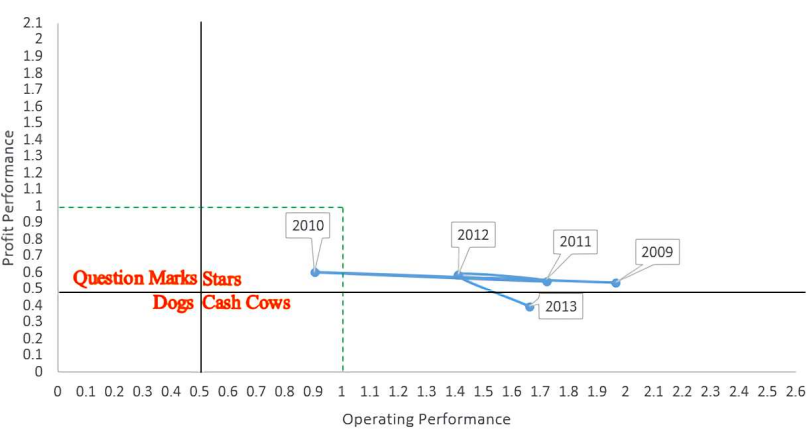

KGI SR Efficiency value

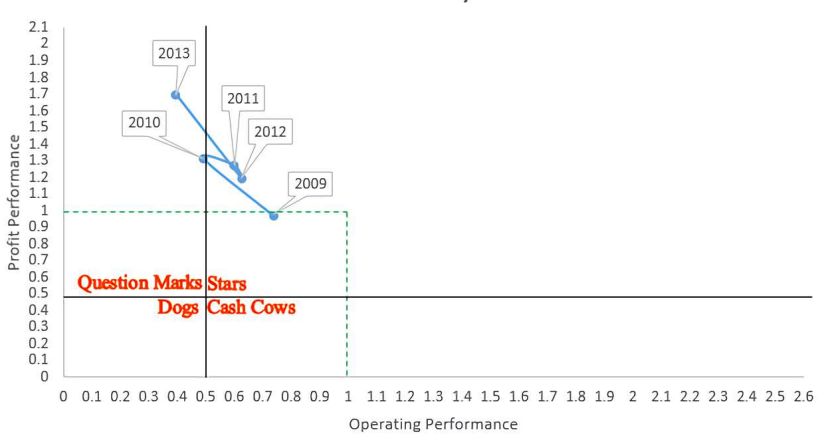

HRS SR Efficiency value

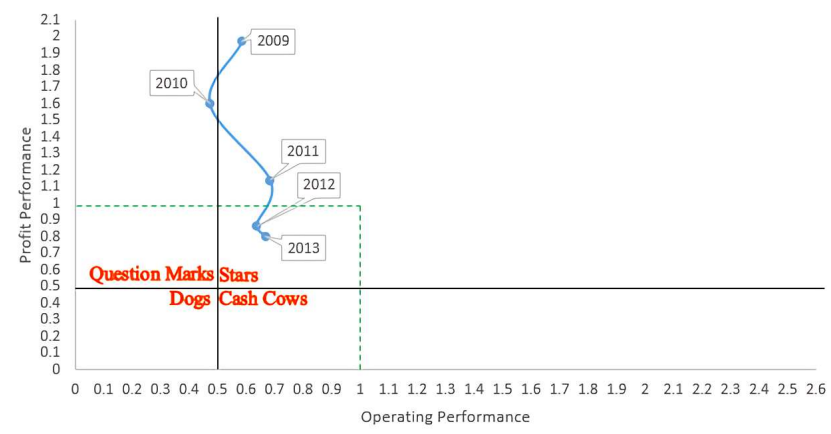

CCS SR Efficiency value

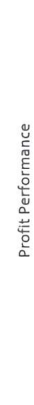



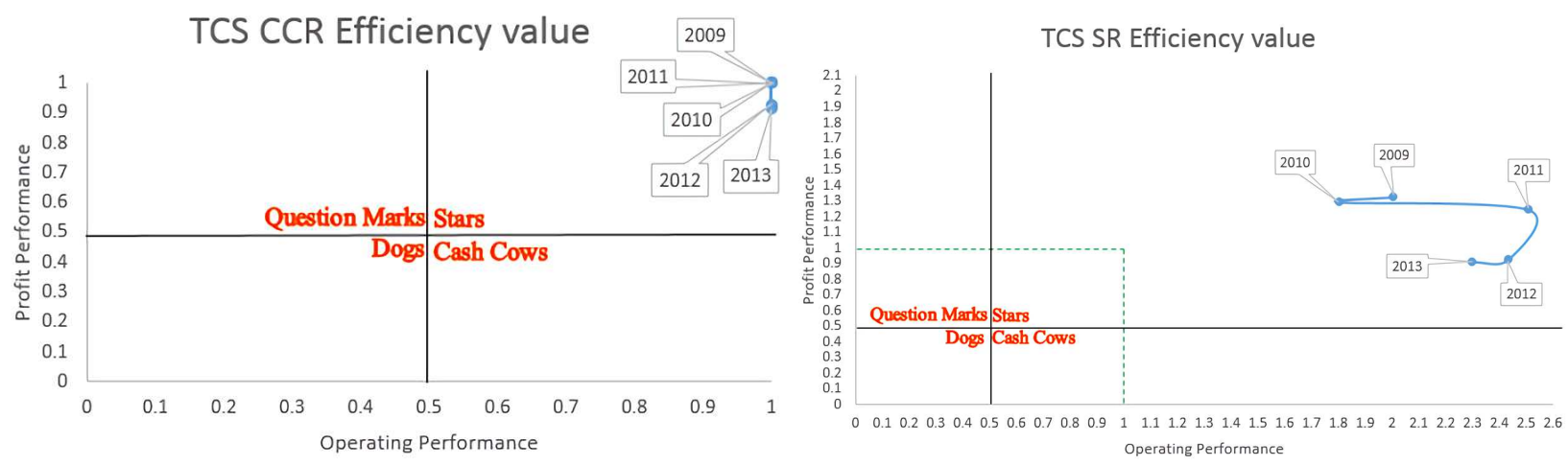

TCHS CCR Efficiency value
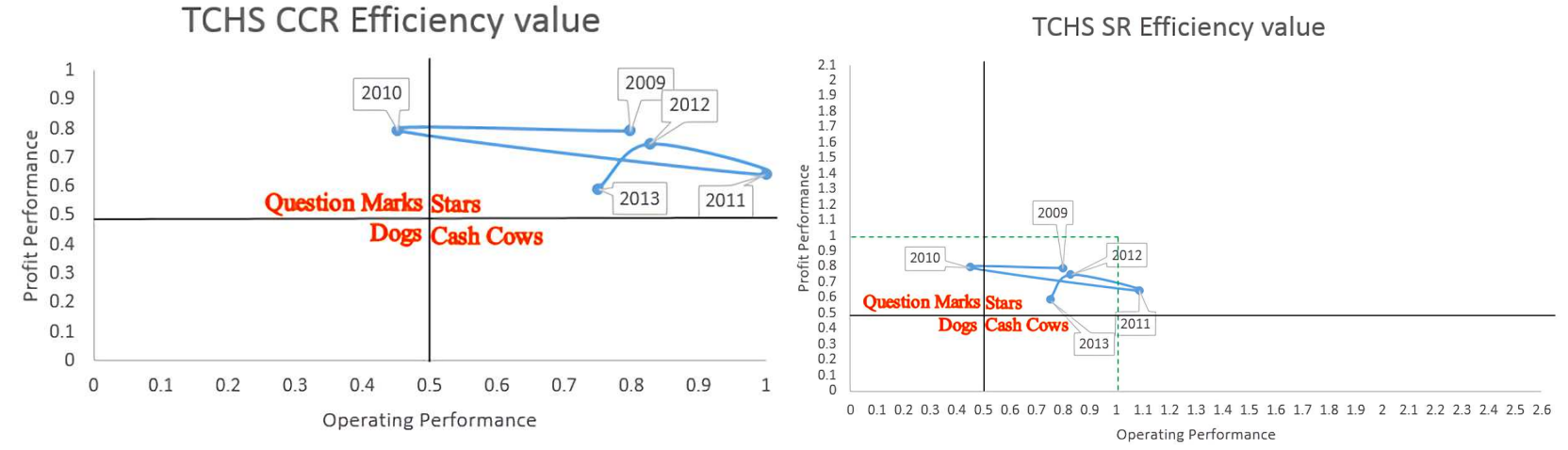

TCSC CCR Efficiency value
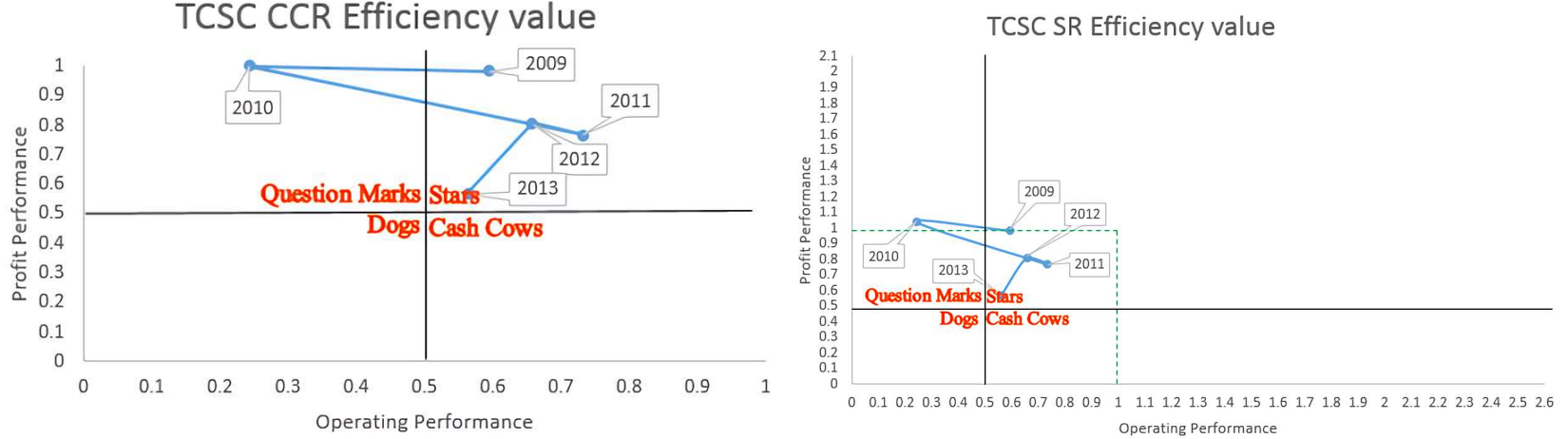

\section{CPAITAL CCR Efficiency value}
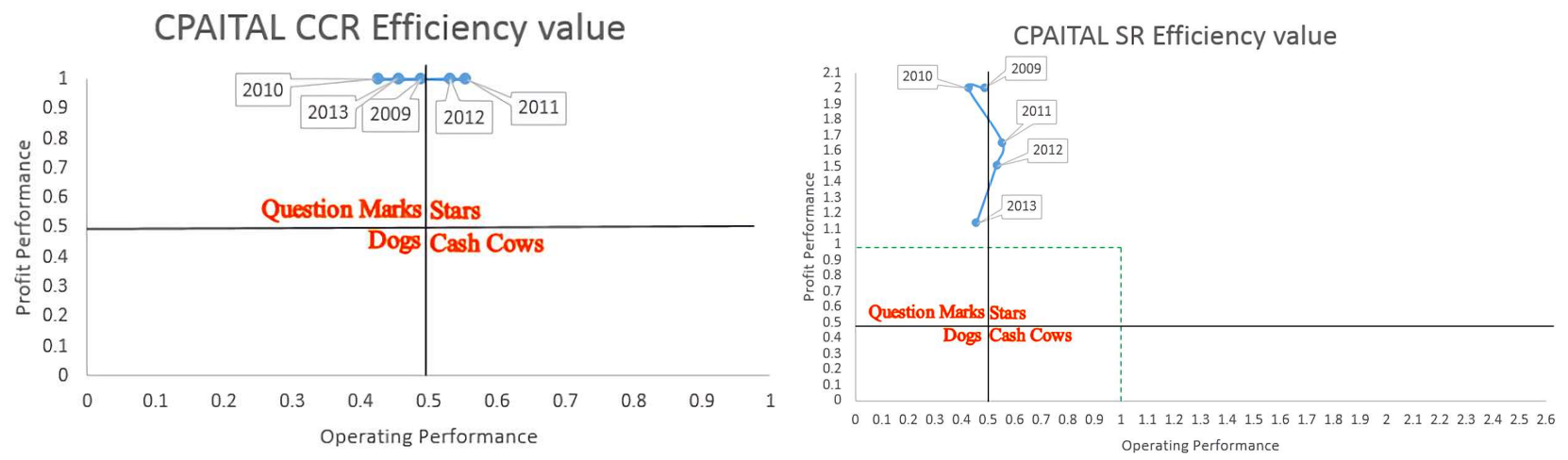

Fig. 6: 2009-2013 company dynamic management strategies 


\section{Conclusion}

The financial market in Taiwan plays an increasingly important role in globalization and financial liberalization and the securities industry is at the center of the capital market. After the subprime-mortgage crisis, differences in scale have expanded among Taiwanese securities firms, while market structure and business environment has also witnessed drastic changes. It is hence necessary to effectively review and adjust company strategies in the highly competitive market. How to objectively evaluate the industry's performance post-crisis has become an issue worthy of attention.

This study presents a two-stage DEA model based on the operational stage and profit-making stage that applies the CCR and Super Radial tool. In light of the Pearson correlation instrument, this paper determines the key evaluation criteria for securities firms: operational expenses, total assets, number of employees, equipment, self-operating business revenues, brokerage revenues, underwriting revenues and interest revenues. Then, calculation of the efficiency value of the operational/profit-making stage is performed using the CCR and Super Radial methodologies. The Super Radial model is used to resolve the multiple efficiency value (efficiency=1) and can obtain the real rank from all CCR results. For example, the operational stage of the efficient DMUs from the CCR model has CIS and TCS (efficiency $=1$ ), while the profit-making stage of efficient DMUs from the CCR model has HRS, TCS and CAPTIAL (efficiency $=1$ ) in the 2009 period. For this scenario, the efficient samples are unable to obtain the real performance and final rank. Therefore, the Super Radial model re-evaluates the new efficiency from the efficient samples in CCR model. The new efficiency of CIS and TCS in the operational stage are: CIS (1.965) and TCS (2.005). The results indicate that TCS had the optimal performance in the operational stage in 200. The new efficiency of HRS, TCS and CAPTIAL in the profit-making stage are: HRS (1.973), TCS (1.326) and CAPTIAL (2.001). The results indicate that CAPITAL had the optimal performance in the profit-making stage in 2009.

Based on the above, the Super Radial results suggest that in 2009, TCS ranked first in operational efficiency, while CAPITAL ranked first in profit-making efficiency; in 2010, TCS ranked first in operational efficiency, while CAPITAL ranked first in profit-making efficiency; in 2011, TCS ranked first in operational efficiency, while CAPITAL ranked first in profit-making efficiency; in 2012, TCS ranked first in operational efficiency, while ML ranked first in profit-making efficiency; in 2013, TCS ranked first in operational efficiency, while KGI ranked first in profit-making efficiency. Overall, regarding the performance of the operational stage after the financial crisis, TCS performed better than the other securities dealers, while during the profit-making stage, CAPITAL had the best performance.

In order to observe the strategic position and trajectory of individual firms, this paper integrates the two-stage efficiency values with the BCG Matrix in the analysis of strategic positioning. The BCG model is an instrument that can separate four quadrants (Stars, Cash Cows, Question Marks and Dogs) from the business performance by using a horizontal axis and vertical axis. The Stars quadrant is the goal of enterprises from the efficiency perspective. Therefore, BCG not only obtains a business strategy for managers, but also assists them in allocating resources and developing strategies. For instance, this study develops the BCG strategic position chart and trajectory on the basis of the efficiency value obtained from the operational performance and profitmaking performance. There are three sample points (three years) in the Question Marks quadrant of the BCG matrix post-crisis (five years) for PSC's firm efficiency. The managers of PSC could enhance the operational efficiency and thus achieve the objective of its business (the Stars strategy). Furthermore, the strategic trajectory is drawn by connecting five sample points in the BCG strategic chart, which may help managers to browse the variations of business strategies post-crisis so as to revise their firm's operating goals.

The non-parametric statistical method is applied for analysis of the differences between the single-stage and two-stage efficiency values. The environmental variables include company size (large and small), establishment time (new and old) and service size (large and small). The results suggest that, after the financial crisis, the securities industry's operational and profit-making performances are not affected by company size (large and small), establishment time (new and old), or service size (large and small).

The performance evaluation procedure and results proposed in this study are based on the two-stage concept to solve the problem of the DEA black box, while establishing the two-stage performance evaluation procedure, including operational efficiency and profitmaking efficiency. The CCR and Super Radial models are used to analyze the operational and profit-making efficiency of the securities industry. Moreover, the BCG matrix is applied in the categorization and analysis of management strategies. Finally, the environmental variables are used to verify whether the operational and profit-making efficiency values have significant differences after the Financial Tsunami, in order to learn the impact of environmental variables on securities industry efficiency values after the Financial Tsunami. The contribution of this study is to establish an integrated evaluation method and research model to provide the academic community with an innovative evaluation method for the securities industry. In practice, this study provides the securities industry with an 
objective and serious evaluation procedure for senior managers and decision makers in the securities industry for the measurement of efficiency.

\section{Acknowledgement}

We thank the anonymous reviewers and the editor for their valuable comments, insights and suggestions.

\section{Author's Contributions}

Cheng-Shian Lin: Coordinated the mouse work, questionnaire design and distribution and data analysis.

Chun-Yueh Lin: Participated in all experiments, data collection and contributed to the writing of the manuscript.

\section{Ethics}

This study is the author's original research and has not been published anywhere else.

\section{References}

Andersen, P. and N.C. Petersen, 1993. A procedure for ranking efficient units in data envelopment analysis. Management Sci., 39: 1261-1264.

Aubuchon, C.P. and D.C. Wheelock, 2010. The geographic distribution and characteristics of US bank failures, 2007-2010: Do bank failures still reflect local economic conditions? Federal Reserve Bank St. Louis Rev., 92: 395-415.

Avkiran, N.K., 2011. Association of DEA superefficiency estimates with financial ratios: Investigating the case for Chinese banks. Omega, 39: 323-334.

Barth, J.R., C. Lin, Y. Ma, J. Seade and F.M. Song, 2013. Do bank regulation, supervision and monitoring enhance or impede bank efficiency? J. Bank. Finance, 37: 2879-2892.

Charnes, A., W.W. Cooper and E. Rhodes, 1978. Measuring the efficiency of decision making units. Eur. J. Operat. Res., 2: 429-444.

Chang, M.C. and A.H. Tu, 2011. The effects of 'Fear' on volatility-trading volume relationship: Evidence from Taiwan's markets during the financial tsunami. Applied Finance, 2: 302-325.

Chen, I.J., 2014. Financial crisis and the dynamics of corporate governance: Evidence from Taiwan's listed firms. Int. Rev. Econom. Finance, 32: 3-28.

Chen, Y.C., Y.H. Chiu, C.W. Huang and C.H. Tu, 2013. The analysis of bank business performance and market risk-Applying Fuzzy DEA. Econom. Modell., 32: 225-232.

Choi, J.W., 2013. The 2007-2010 US financial crisis: Its origins, progressions and solutions. J. Econom. Asymmetries, 10: 65-77.
Chor, D. and K. Manova, 2012. Off the cliff and back? Credit conditions and international trade during the global financial crisis. J. Int. Econom., 87: 117-133.

Cummins, J.D. and M.A. Weiss, 2013. Analyzing Firm Performance in the Insurance Industry Using Frontier Efficiency and Productivity Methods. In: Handbook of Insurance, Dionne, G. (Ed.), Springer Science and Business Media, New York, ISBN-10: 1461401550, pp: 795-861.

DeYoung, R. and G. Torna, 2013. Nontraditional banking activities and bank failures during the financial crisis. J. Financial Intermediation, 22: 397-421.

DGBAS, 2014. 2007-2013 Taiwan's unemployed population and unemployment rate. Directorate General Budget, Account. Statist. Executive Yuan, R.O.C.

Ebrahimnejad, A., M. Tavana, F.H. Lotfi, R. Shahverdi and M. Yousefpour, 2014. A three-stage data envelopment analysis model with application to banking industry. Measurement, 49: 308-319.

Erkens, D.H., M. Hung and P. Matos, 2012. Corporate governance in the 2007-2008 financial crisis: Evidence from financial institutions worldwide. J. Corporate Finance, 18: 389-411.

Fang, C.Y. and J.L. Hu, 2012. Environment and statistical noise-adjusted efficiency under zero-sum gains with an application to securities firms. Taiwan J. Applied Econom.

Fenn, P., D. Vencappa, S. Diacon, P. Klumpes and C. O'Brien, 2008. Market structure and the efficiency of European insurance companies: A stochastic frontier analysis. J. Bank. Finance, 32: 86-100.

Francis, B., I. Hasan and Q. Wu, 2013. The benefits of conservative accounting to shareholders: Evidence from the financial crisis. Account. Horizons, 27: 319-346.

Goedde-Menke, M., T. Langer and A. Pfingsten, 2014. Impact of the financial crisis on bank run risk-danger of the days after. J. Bank. Finance, 40: 522-533.

Goldsmith-Pinkham, P. and T. Yorulmazer, 2010. Liquidity, bank runs and bailouts: Spillover effects during the Northern Rock episode. J. Financial Services Res., 37: 83-98.

Gulati, R., R. Gulati, S. Kumar and S. Kumar, 2017. Analysing banks' intermediation and operating efficiencies using the two-stage network DEA model: The case of India. Int. J. Productivity Performance Manage., 66: 500-516.

Gibbons, J.D., 1993. Nonparametric Statistics: An Introduction. 1st Edn., Sage Publications, Newbury Park, ISBN-10: 0803939515, pp: 87.

Hedley, B., 1977. Strategy and the "business portfolio. Long Range Planning, 10: 9-15. 
Halkos, G.E. and N.G. Tzeremes, 2013. Estimating the degree of operating efficiency gains from a potential bank merger and acquisition: A DEA bootstrapped approach. J. Bank. Finance, 37: 1658-1668.

Haltofová, P. and P. Štěpánková, 2014. An Application of the Boston Matrix within Financial Analysis of NGOs. Procedia-Social Behavioral Sci., 147: 56-63.

Holod, D. and H.F. Lewis, 2011. Resolving the deposit dilemma: A new DEA bank efficiency model. J. Bank. Finance, 35: 2801-2810.

Ioana, A., V. Mirea and C. Bălescu, 2009. Analysis of service quality management in the materials industry using the bcg matrix method. Amfiteatru Econom. Rev., 11: 270-276.

Farrell, M.J., 1957. The measurement of productive efficiency. J. Royal Statistical Society. Series A (General), 120: 253-290.

Kang, H.H. and S.B. Liu, 2014. The impact of the 2008 financial crisis on housing prices in China and Taiwan: A quantile regression analysis. Econom. Modell., 42: 356-362.

Liu, S., 2008. Commission deregulation and performance of securities firms: Further evidence from Japan. J. Econom. Bus., 60: 355-368.

Macpherson, A.J., P.P. Principe and Y. Shao, 2013. Controlling for exogenous environmental variables when using data envelopment analysis for regional environmental assessments. J. Environ. Manage., 119: 220-229.

Martin, R., 2011. The local geographies of the financial crisis: from the housing bubble to economic recession and beyond. J. Econom. Geography, 11: 587-618.

Mann, H.B. and D.R. Whitney, 1947. On a test of whether one of two random variables is stochastically larger than the other. Annals Mathematical Statistics, 18: 50-60.

Shin, H.S., 2009. Reflections on Northern Rock: The bank run that heralded the global financial crisis. J. Econom. Perspectives, 23: 101-109. DOI: 10.1257/jep.23.1.101
Simar, L. and P.W. Wilson, 2011. Two-stage DEA: Caveat emptor. J. Productivity Anal., 36: 205-218.

Spee, A.P. and P. Jarzabkowski, 2009. Strategy tools as boundary objects. Strategic Organization, 7: 223-232.

Staub, R.B., G. da Silva e Souza and B.M. Tabak, 2010. Evolution of bank efficiency in Brazil: A DEA approach. Eur. J. Operat. Res., 202: 204-213.

TIER, 2014. 2007-2013 Taiwan's total exports and yearly growth rates of all industries. Taiwan Institute Econom. Res.

Wang, K., W. Huang, J. Wu and Y.N. Liu, 2014. Efficiency measures of the Chinese commercial banking system using an additive two-stage DEA. Omega, 44: 5-20.

Wilcoxon, F., S.K. Katti and R.A. Wilcox, 1970. Critical values and probability levels for the Wilcoxon rank sum test and the Wilcoxon signed rank test. Selected Tables Mathematical Statistics, 1: 171-259.

WB, 2009. Swimming against the tide: How developing countries are coping with the global crisis. Horsham, United Kingdom.

Xiaofang, W. and C. Kesheng, 2009. An analysis on dynamic efficiency of China securities industry. Indus. Econom. Res., 2: 1-8.

Yeh, C.P., K.M. Wang and K.C. Chai, 2010. Measuring the efficiency of securities companies by corporate governance in a financial holding and non-financial holding system. Expert Syst. Applic., 37: 4671-4679.

\section{Sources of Figures}

Figure 1: Source: TIER (2014)

Figure 2: Source: DGBAS (2014)

Figure 3: * Source: Haltofová and Štěpánková (2014) 